\title{
JOB INSECURITY, BURNOUT AND WORK ENGAGEMENT: THE IMPACT OF POSITIVE AND NEGATIVE AFFECTIVITY
}

\author{
J BOSMAN \\ WorkWell: Research Unit for People, Policy \& Performance \\ Vaal Triangle Campus \\ North-West University \\ S ROTHMANN \\ WorkWell: Research Unit for People, Policy \& Performance \\ Potchefstroom Campus \\ North-West University \\ JH BUITENDACH \\ WorkWell: Research Unit for People, Policy \& Performance \\ Vaal Triangle Campus \\ North-West University
}

\begin{abstract}
The objective of this study was to investigate the relationship between job insecurity, affectivity, burnout and work engagement of employees $(N=297)$ in a government organisation. A cross-sectional survey design was used. The Job Insecurity Questionnaire, Affectometer 2, Oldenburg Burnout Inventory, and Utrecht Work Engagement Scale were used as measuring instruments. Job insecurity as well as negative and positive affectivity had main effects on burnout and work engagement. Negative affectivity also interacted with job insecurity to influence the burnout and work engagement of employees. No interaction effects were found between positive affectivity and job insecurity.
\end{abstract}

\section{OPSOMMING}

Die doelstelling van hierdie studie was om die verband tussen werksonsekerheid, affektiwiteit, uitbranding en werksbegeestering van werknemers $(N=297)$ in 'n staatsorganisasie te ondersoek. Daar is gebruik gemaak van 'n dwarsdeursnee-opname-ontwerp. Die Werksonsekerheidsvraelys, Affectometer 2, die Oldenburg-Uitbrandingsvraelys en die Utrecht-Werksbegeesteringskaal is as meetinstrumente gebruik. Die resultate het daarop gedui dat werksonsekerheid, sowel as negatiewe en positiewe affektiwiteit hoofeffekte op uitbranding en werksbegeestering gehad het. Uitbranding en begeestering is ook deur die interaksie tussen negatiewe affektiwiteit en werksonsekerheid beinvloed. Geen interaksie-effekte is tussen positiewe affektiwiteit en werksonsekerheid gevind nie.

\begin{abstract}
Now more than ever, South African companies are exposed to the effects of the world economy, technological advancement and strong international competition. As noted by Martins (2000), employers attempt to move toward greater flexibility by expanding and shrinking the workforce to correspond with shifting production and service demands, resulting in a sense of job insecurity. According to Maslach, Schaufeli and Leiter (2001), the impact of the changing world of work is perhaps most evident in changes in the psychological contract. Employees are expected to give more in terms of time, effort, skills, and flexibility, whereas they receive less in terms of career opportunities, lifetime employment, and job security. According to Hellgren, Sverke and Isaksson (1999), working life has been subject to dramatic change over the past decades and numerous organisations have engaged in large-scale workforce reductions in order to cut costs and improve organisational effectiveness and competitive ability.
\end{abstract}

Besides being a requirement for a steady income and adult socio-economic status, an individual's occupation is also a source of socialisation, providing opportunities for personal growth and development, including the positive experience of oneself in a core social role, and allows for partaking in societal networks beyond primary groups (Siegrist et al., 2004). According to Bridges (1995), the identities of most citizens of industrialised countries are defined in terms of their jobs. Through jobs, individuals are connected to a wider community and find structure and purpose. Given the variety of functions fulfilled by employment in advanced societies, employment continues to play an important role in the health and well-

Requests for copies should be addressed to: J Bosman, bpkjb@puk.ac.za being of adults (Siegrist et al., 2004). The perception that the current job might be lost reduces well-being, since, in our society, work constitutes the key to social participation and recognition (De Witte, 1999).

Besides those employees anticipating potential job loss, job insecurity also relates to those who retained their positions ("survivors") after having undergone a redundancy or downsizing programme. According to Baruch and Hind (1999), "survivors" experience the adverse effects of change as profoundly as those who have left. Numerous negative effects of "survivor syndrome" have been covered in the literature, including burnout, low morale, decreased commitment, reduced loyalty, inefficiency, reduced performance, resignation and cynicism (Baruch \& Hind, 1999). Exploratory research undertaken by De Witte (1999) confirmed that job insecurity was as harmful to the well-being of individuals as unemployment itself. Job insecurity is likely to contribute to burnout and lower work engagement, because it erodes the notion of reciprocity - which is crucial in maintaining wellbeing (Maslach et al., 2001). Previous research pointed toward the significant role that cognitive appraisal plays in the stressstrain link, with some researchers (Parkes, 1994) arguing that those who exhibit negative affectivity are prone to react more adversely to perceived stress than those with low negative affectivity (Mak \& Mueller, 2001)

The management of the government department that was the focus of this study was concerned about the general well-being of the workforce, noting that they present with unusually high levels of absenteeism and turnover. The employees of this department are reported to be generally insecure regarding their occupational futures, many not knowing how their desired 
occupational futures fit in with their potential career paths within the organisation. As noted by Rothmann (2003), tracking employees' effectiveness in coping with demands of the new world of work, and stimulating their growth in areas that could possibly impact on individual well-being and organisational efficiency and effectiveness are crucial. Therefore, this study, which investigates the relationship between job insecurity, burnout and engagement, as well as the role that affectivity plays in these relationships, is deemed important.

The objective of this study was to investigate the relationship between job insecurity, affectivity, burnout and work engagement of employees in a government organisation.

\section{Job insecurity, burnout and work engagement}

According to De Witte $(1997,1999)$, the subject of job insecurity relates to people in their work context who fear that they may lose their jobs and become unemployed. Greenhalgh and Rosenblatt (1984, p. 438) define job insecurity as a "sense of powerlessness to maintain desired continuity in a threatened job situation". Job insecurity has been defined according to a global viewpoint, signifying the threat of job loss or job discontinuity (Caplan, Cobb, French, van Harrison \& Pinneau, 1980; De Witte, 1999). Generally, this definition has been applied in the context of organisational crisis or change, in which job insecurity is considered as a first phase of the process of job loss (Ferrie, 1997; Joelson \& Wahlquist, 1987). Researchers who adopt a multidimensional definition of job insecurity argue that job insecurity refers not only to the degree of uncertainty, but also to the continuity of certain dimensions, such as opportunities for promotion (Ashford, Lee \& Bobko, 1989; Borg \& Elizur, 1992; Rosenblatt \& Ruvio, 1996). Hellgren, Sverke and Isaksson (1999) indicate that the terms quantitative and qualitative job insecurity are used to distinguish between these two dimensions of job insecurity. Quantitative job insecurity refers to concern for the future existence of the present job, whereas qualitative job insecurity refers to perceived threats of impaired quality in the employment relationship (e.g. deterioration of working conditions, lack of career opportunities, and/or a salary decrease).

Job insecurity consistently presents itself as a stressor (De Witte, 1999; Van Vuuren, 1990). With regard to consequences, a distinction is made between stress reactions and coping behaviour. Stress reactions refer to the consequences of the stressor for psychological well-being, while coping refers to the way in which the person deals with stress (Van Vuuren, 1990). Van Vuuren (1990), who views job insecurity as an overall concern, emphasises that job insecurity has the following components: Firstly, it is a subjective experience or perception, as different employees might perceive the same situation differently. Secondly, job insecurity implies uncertainty regarding the future and doubts about the continuation of the job. De Witte (2000) conceptualises job insecurity from a global, two-dimensional perspective, consisting of affective and cognitive job insecurity. Cognitive job insecurity relates to the perceived likelihood of job loss, whereas affective job insecurity relates to fear of job loss.

Probst (2002) explains that, from an affective events theory perspective, work environment features and events are subject to cognitive appraisal of whether and to what extent such work events and features will aid or obstruct the attainment of goals. If goal obstruction is identified and there is a perceived imbalance between the environmental demands and the employee's ability to cope with those demands, stress results, the extent of which varies according to dispositions and available resources. This strain may become evident at a physiological, behavioural or psychological level - or any combination thereof. Probst (2002) explains that, for this reason, when stress exists, work attitudes and affective reactions are expected to be negative.
From the person-environment fit perspective, psychological adjustment is viewed as the congruence between the employee and workplace characteristics. According to Probst (2002), stress value depends on the perceived imbalance between an individual's perceptions of the demands made by the environment and the individual's perceived ability and motivation to cope with those demands. Job insecurity could be perceived by an employee as a change or precursor to change demanding adaptation, which may be difficult to meet (Probst, 2002). Failure to cope with potential future unemployment or loss of job features may have significant consequences. Bergh and Theron (2003) indicate that symptoms such as stress, role conflict, role ambivalence and burnout may be indicative of incongruent fit in the workplace.

Based on the above review, it is perceived that increased job insecurity, as a stressor, will be associated with increased levels of burnout and decreased levels of work engagement. Burnout is a particular, multidimensional and chronic stress reaction that goes beyond the experience of mere exhaustion, and is seen as the final step in a progression of unsuccessful attempts to cope with a variety of negative stress conditions (Rothmann, Jackson \& Kruger, 2003). Maslach et al. (2001, p. 399) define burnout as a "psychological syndrome in response to chronic interpersonal stressors on the job". Schaufeli and Enzmann (1998, p. 36) define the concept as "a persistent, negative, work-related state of mind in 'normal' individuals that is primarily characterised by exhaustion, accompanied by distress, a sense of reduced effectiveness, decreased motivation, and the development of dysfunctional attitudes and behaviours at work"

The Maslach Burnout Inventory (MBI) is probably the most popular and frequently used measure of burnout. The MBI reflects three burnout dimensions, being emotional exhaustion, cynicism/depersonalisation and reduced efficacy/ accomplishment. According to Maslach et al. (2001), the exhaustion (both helping and non helping professions) component of job burnout relates to the basic individual stress aspect of burnout, referring to feelings of being overextended and depleted of one's emotional and physical resources. These researchers furthermore note that exhaustion is considered the central quality and most obvious symptom of burnout. The cynicism (non-helping professions) or depersonalisation (helping professions) component represents the interpersonal context dimension of burnout, referring to negative, callous, or excessively detached responses to various aspects of the job. The reduced efficacy (non-helping professions) or accomplishment (helping professions) component is linked to the self-evaluation dimension of burnout, referring to feelings of incompetence and a lack of achievement and productivity at work.

The Oldenburg Burnout Inventory (OLBI) (Demerouti, Bakker, Vardakou \& Kantas, 2003) has recently been developed as an alternative measure of burnout. The OLBI includes both core dimensions of burnout, known as exhaustion and disengagement (cynicism/depersonalisation), thus conceptualising burnout as a syndrome of work-related negative experiences, including feelings of exhaustion and disengagement from work. From this perspective, exhaustion is defined as the result of prolonged and intense physical, cognitive and affective strain, resulting from prolonged exposure to specific work stressors (Demerouti, Bakker, Nachreiner \& Ebbinghaus, 2002). The disengagement aspect of burnout refers to emotions regarding the work task (e.g. uninteresting and no longer challenging), as well as a devaluation and mechanical execution of one's work. Disengagement represents a wide-ranging and intensive reaction in terms of an emotional, cognitive and behavioural rejection of the job and it describes occupational disillusionment. 
In line with the increased focus of psychology on human strengths and optimal functioning, work engagement, although related to burnout, is viewed as the theoretical antithesis of burnout. Maslach and Leiter (1997) redefine burnout as an erosion of engagement with the job. However, Schaufeli and Bakker (2001) define engagement as a positive, fulfilling, work-related state of mind, characterised by vigour, dedication and absorption. Schaufeli, Salanova, GonzálezRomá and Bakker (2002) explain that vigour (opposite pole of exhaustion) is characterised by high energy levels, mental resilience when working, willingness to exert effort into one's work, and to persist even in the face of adversity. Dedication (the opposite pole of cynicism) is related to enthusiasm, inspiration, pride, challenge and a sense of significance; and absorption refers to a state where time passes quickly and where the individual has difficulty in detaching himself/herself from work.

Westman, Etzion and Danon (2001), who researched job insecurity and crossover of burnout in married couples (98 couples), found a positive correlation between job insecurity and burnout, with regard to both males and females. These researchers concluded (p. 478) that their findings corroborated the results of Dekker and Schaufeli (1995) and Landsbergis (1988) that the prolonged chronic exposure to job insecurity could lead to a wearing out of resources and a feeling of exhaustion. Hellgren et al. (1999) found that quantitative job insecurity was related to stress symptoms such as ill health, sleeping problems and distress and that these problems also tend to transfer to nonwork settings. Qualitative job insecurity related primarily to attitudinal outcomes, such as job dissatisfaction and propensity to leave.

One would only expect a person to develop burnout after experiencing particularly severe job insecurity for a prolonged period of time - something that is not applicable to this particular study population. A practically significant relationship between job insecurity and burnout may, however, be obtained when using a sample that has been experiencing a high level of job insecurity for a substantial amount of time (for example employees working in an organisation that has been working toward downsizing for some time). However, within the context of this study, it is expected that job insecurity will show an association with reduced levels of work engagement. Based on the cited research, the following hypotheses are proposed:

H1: A significant positive relationship exists between (cognitive and affective) job insecurity and burnout.

H2: A significant negative relationship exists between (cognitive and affective) job insecurity and work engagement.

\begin{abstract}
Affectivity
Positive affect and negative affect, which are aspects of employees' happiness, may, on their own or in interaction with job insecurity lead to burnout and work engagement. Affect can be assessed as a short-term state or long-term trait. Watson (2002) explains that, viewed as a long-term trait, these constructs are typically referred to as negative and positive "affectivity", as opposed to "affect", which refers to a shortterm, fleeting state of emotions.
\end{abstract}

According to Meeks and Murrell (2001), negative affectivity could be defined as an intra-psychic determinant that controls an individual's view of the world, where an individual will interpret the world and see himself/herself in unhappy and pessimistic terms. Mak and Mueller (2001) conceptualise negative affectivity as reflecting neuroticism, a low level of self-esteem and frequent negative emotionality, noting that individuals high in trait negative affectivity are prone to experiencing and reporting high levels of subjective stress and strain outcomes. Individuals high on negative affectivity tend to be easily distressed, agitated, upset, pessimistic, and dissatisfied (Chiu \& Kosinski, 1997). In contrast, individuals who measure high on positive affectivity experience frequent and intense episodes of pleasant, pleasurable mood and are generally cheerful, enthusiastic, energetic, confident, and alert (Watson, 2002). Conversely, those measuring low on positive affectivity report reduced levels of happiness, excitement, vigour and confidence (Watson, 2002).

Abraham (1998) notes that, viewed as a stable trait, both in the temporal and cross-situational sense, negative affectivity may influence stress-outcome relationships. In their research, Roskies, Louis-Guerin and Fournier (1993) investigated the relationship between personality traits, job insecurity and employee well-being. These researchers found that individuals high on negative affectivity do not always perceive the outcomes of job insecurity as more severe than those measuring low on this trait, but may report lower wellbeing as a result of their elevated initial values. Research by Roskies et al. (1993) demonstrated that individuals with high levels of negative affectivity tend to report consistently more stress reactions than individuals measuring low on this trait, as well as that individuals measuring high on positive affectivity report higher levels of well-being.

Roskies et al. (1993) found that mood dispositions hold more predictive value with regard to stress than job insecurity perceptions. Hellgren, Sverke and Isaksson (1999) found that taking mood dispositions into account improves the prediction of the outcomes of job insecurity. Therefore, positive and negative affectivity might have main effects on burnout and work engagement. Furthermore, affectivity can interact with job insecurity to affect burnout and work engagement. According to Baron and Kenny (1986), a moderator is a qualitative (e.g. gender) or quantitative (e.g. affectivity) variable that affects the direction and/or strength of the relation between an independent and a dependent variable. In a correlation analysis framework, a moderator is a third variable that affects the zero-order correlation between two other variables, and the moderator effect may be said to occur where the direction of the correlation changes.

Based on the cited research, the following hypotheses are proposed:

H3: Positive and negative affectivity have main effects on burnout and work engagement.

H4: Positive and negative affectivity interact with job insecurity to influence burnout and work engagement.

\section{METHOD}

\section{Research design}

A cross-sectional survey design was used to describe the information on the population collected at that time (Shaughnessy \& Zechmeister, 1997).

\section{Participants}

The entire population of 500 employees working in the government organisation in Gauteng was targeted for this research, but a response rate of only 59\% (297 participants) was obtained. The population included workers at all levels, ranging from semi-skilled to professionals. The lowest level employees had a level of literacy adequate to allow for valid completion of questionnaires. The biographical characteristics of the study population are detailed in Table 1. 
TABLE 1

Characteristics OF THE PARTICPANTS $(N=297)$

\begin{tabular}{|c|c|c|c|}
\hline Item & Category & Frequency & Percentage \\
\hline \multirow[t]{4}{*}{ Cultural group } & Black (1) & 185 & 62,3 \\
\hline & White (2) & 56 & 18,9 \\
\hline & Other (3) & 34 & 11,4 \\
\hline & Total & 275 & 92,6 \\
\hline \multirow[t]{3}{*}{ Gender } & Male (1) & 145 & 48,8 \\
\hline & Female (2) & 142 & 47,5 \\
\hline & Total & 286 & 96,3 \\
\hline \multirow[t]{6}{*}{ Age } & 24 years and younger (1) & 27 & 9,1 \\
\hline & 25 - 35 years $(2)$ & 105 & 35,4 \\
\hline & $36-45$ years $(3)$ & 69 & 23,2 \\
\hline & $46-55$ years $(4)$ & 47 & 15,8 \\
\hline & 56 years and older (5) & 17 & 5,7 \\
\hline & Total & 265 & 89,2 \\
\hline \multirow[t]{5}{*}{ Qualification } & Grade 10 to 12 (1) & 139 & 46,8 \\
\hline & Diploma (2) & 77 & 25,9 \\
\hline & Degree (3) & 55 & 18,5 \\
\hline & Postgraduate Degree (4) & 24 & 8,1 \\
\hline & Total & 295 & 99,3 \\
\hline \multirow[t]{6}{*}{ Tenure } & Less than 1 year $(1)$ & 47 & 15,8 \\
\hline & $2-5$ years $(2)$ & 74 & 24,9 \\
\hline & $6-10$ years $(3)$ & 68 & 22,9 \\
\hline & 11 - 20 years $(4)$ & 59 & 19,9 \\
\hline & Longer than 20 years (5) & 37 & 12,5 \\
\hline & Total & 285 & 96,0 \\
\hline
\end{tabular}

Sixty percent of the participants were black. The majority of participants fell in the 25 to 35 years and the 36 to 45 years age groups, and $47 \%$ had a grade 10 to 12 level of education. The majority of the study population have worked for the organisation for between 2 and 5 years (25\%), and for between 6 and 10 years $(23 \%)$.

\section{Measuring instruments}

The Job Insecurity Questionnaire (JIQ) (De Witte, 2000), the Affectometer 2 (AFM 2) (Kammann \& Flett, 1983), the Oldenburg Burnout Inventory (OLBI) (Demerouti, Bakker, Vardakou \& Kantas, 2003) and the Utrecht Work Engagement Scale (UWES) (Schaufeli, Salanova, González-Romá \& Bakker, 2002) were used in this study. Biographical information was also gathered regarding race, education, age and tenure.

The 11 items of the Job Insecurity Questionnaire (JIQ) (De Witte, 2000), which was used as a measure of job insecurity, summarise both the cognitive and affective dimensions of job insecurity and are arranged along a five-point scale ranging from 1 (strongly agree) to 5 (strongly disagree). An example of a question relating to cognitive job insecurity would be, "I think that I will be able to continue working here", whereas an example of a question relating to affective job insecurity would be, "I fear that I might lose my job". The items of the JIQ, measuring global job insecurity, are reported to have a Cronbach alpha coefficient of 0,92 and both scales (cognitive and affective) were shown to be highly reliable, with the six items measuring cognitive job insecurity displaying a Cronbach alpha coefficient of 0,90 , and the five items of the affective job insecurity displaying a Cronbach alpha coefficient of 0,85 (De Witte, 2000). According to De Witte (2000), the content of these two scales do not overlap, but have a high underlying correlation $(r=0,76)$. In terms of South African research, Heymans (2002) obtained an alpha coefficient of 0,81 for the JIQ, and Elbert (2002) obtained an alpha coefficient of 0,84 .
The Affectometer 2 (AFM 2) (Kammann \& Flett, 1983) was used to measure affectivity. The AFM 2 is a 20 -item self-report scale measuring the balance of positive and negative feelings in recent experience. Questions are rated on a scale ranging from 1 (not at all) to 5 (all the time). Examples pertaining to the negative affectivity scale would include, "I wish I could change some part of my life", and "I feel like a failure", whereas items from the positive affectivity scale would include "My life is on the right track", and "I can handle any problems that come up". Kammann and Flett (1983) obtained Cronbach alpha coefficients of 0,95 for the scale, as well as indications of validity. The AFM shows correlations of 0,74 with the General Well-being Schedule, and $-0,62$ with an ad hoc list of somatic complaints, which indicate acceptable validity. Using a simple principal component analysis on the 10 items of the positive affectivity scale, Jackson and Rothmann (2004) obtained a one-factor solution and a Cronbach's alpha of 0,80 .

The Oldenburg Burnout Inventory (OLBI) (Demerouti et al., 2003) was used as a measure of burnout. The OLBI includes both core dimensions of burnout, known as exhaustion and disengagement (cynicism/depersonalisation). The OLBI consists of 16 items, which are measured on a four-point Likert-type scale ranging from 1 (strongly agree) to 4 (strongly disagree). Eight items are phrased positively, for example, "I always find new and interesting aspects in my work", and the remaining eight are phrased negatively, for example, "There are days when I feel tired before I arrive at work". The exhaustion subscale comprises 8 items, measuring affective, physical and cognitive aspects of burnout. The disengagement subscale comprises 8 items that relate to distancing oneself from one's work. An example of an item from the exhaustion scale would be, "During my work, I often feel emotionally drained", whereas an example of an item from the disengagement scale would be, "I find my work to be a positive challenge". In a study conducted by Demerouti et al. (2002), investigating the convergent validity of the MBI and OLBI by means of multitrait-multimethod analyses, it was found that the latent variables representing both instruments are highly correlated and that all exhaustion and distancing/disengagement items of both instruments load on a single factor. Demerouti et al. (2002) obtained Cronbach alpha coefficients of 0,85 (exhaustion) and 0,84 (disengagement) respectively.

The Utrecht Work Engagement Scale (UWES) (Schaufeli et al., 2002) was used to measure work engagement. This 17 -item questionnaire is arranged along a seven-point frequency scale ranging from 0 (never) to 6 (daily). The UWES has three scales, namely vigour (6 items), dedication (5 items), and absorption (6 items). Examples of items relating to the three dimensions are the following: "I am bursting with energy in my work" (vigour); "I find my work full of meaning and purpose" (dedication); and "When I am working, I forget everything around me" (absorption). High levels of vigour, dedication and engagement point to an individual who experiences a high level of work engagement. Regarding internal consistency, Cronbach coefficients have been determined between 0,68 and 0,91 (Schaufeli et al., 2002). Storm (2002) obtained alpha coefficients of 0,78 (vigour), 0,89 (dedication), and 0,78 (absorption) for the UWES in a South African sample.

\section{Data analysis}

The statistical analysis was carried out with the SPSS rogram (SPSS Inc., 2003), using descriptive statistics, Cronbach's alpha and inter-item correlation coefficients, and Pearson correlation coefficients. A cut-off point of 0,30, which represents a medium effect (Cohen, 1988; Steyn, 2002), was set for the practical significance of correlation coefficients. The significance of differences in exhaustion/disengagement and work engagement scores between low and high (positive and negative) affectivity 
groups was established by means of MANOVA. Structural equation modelling (SEM) methods as implemented by AMOS (Arbuckle, 1997) was used. In the first step, multi-group structural models, which distinguish between individuals scoring high and low on both positive and negative affectivity, were constructed. In the second step, the structural paths between job insecurity on the one hand and burnout and work engagement on the other hand were constrained equal across groups. The $\mathrm{x}^{2}$ statistic and degrees of freedom provide the basis for comparison with the initial multi-group model in which no equality constraints were imposed.

\section{RESULTS}

Regarding the JIQ, structural equation modelling results indicated that a good fit was obtained for both the one-factor JIQ model and the two-factor JIQ model, although the fit of the two-factor model was marginally better than that of the one-factor model. Item 2 ("There is only a small chance that I will become unemployed") of the scale proved to be problematic, not loading on either scale, and was consequently removed from the scale. Rather than presenting with an exhaustion and disengagement scale, factor analysis of the OLBI demonstrated a two-factor structure consisting of engagement (all positively phrased items) and exhaustion/disengagement (the remaining negative phrased exhaustion and disengagement items. The two related factors $(\mathrm{r}=0,64)$ were thus labelled "exhaustion/disengagement" and "engagement". Item 13 ("This is the only type of work I can imagine myself doing"), which appeared to be constructed ambiguously, proved to be problematic, and was thus removed from the scale. Factor analysis of the UWES resulted in a onefactor structure. Factor analysis of the AFM 2 confirmed the two-factor structure, resulting in a positive affectivity and a negative affectivity scale.

Descriptive statistics, Cronbach alpha coefficients and the interitem correlation coefficients of the JIQ, AFM 2, OLBI and UWES for employees working in a government organisation are reported in Table 2.

TABLE 2

Decsriptive statistics, Cronbach Alpha coeffients AND INTER-ITEM CORRELATION COEFFICIENTS OF THE MEASURING INSTRUMENTS

\begin{tabular}{|c|c|c|c|c|c|c|}
\hline Test and subscales & Mean & SD & Skewness & Kurtosis & $\begin{array}{l}\text { Inter- } \\
\text { item r }\end{array}$ & $\alpha$ \\
\hline Cognitive job insecurity & 12,82 & 0,79 & 0,10 & $-0,33$ & 0,32 & 0,70 \\
\hline Affective job insecurity & 13,97 & 0,82 & 0,07 & 0,22 & 0,34 & 0,72 \\
\hline $\begin{array}{l}\text { OLBI Exhaustion/ } \\
\text { disengagement }\end{array}$ & 19,67 & 0,50 & 0,08 & 0,58 & 0,28 & 0,66 \\
\hline OLBI Engagement & 15,87 & 0,56 & 0,26 & 0,23 & 0,24 & 0,71 \\
\hline UWES & 65,23 & 23,39 & $-0,28$ & $-0,53$ & 0,47 & 0,94 \\
\hline $\begin{array}{l}\text { AFM } 2 \text { Negative } \\
\text { affectivity }\end{array}$ & 26,23 & 0,79 & 0,14 & $-0,18$ & 0,29 & 0,80 \\
\hline $\begin{array}{l}\text { AFM } 2 \text { Positive } \\
\text { affectivity }\end{array}$ & 35,87 & 0,69 & $-0,05$ & 0,11 & 0,25 & 0,77 \\
\hline
\end{tabular}

Table 2 shows that acceptable Cronbach alpha coefficients were obtained on all the scales, with the exception of the OLBI Exhaustion/Disengagement subscale, which fell marginally below the 0,70 cut-off point (see Nunnally \& Bernstein, 1994). All of the inter-item correlation coefficients were acceptable (Clark \& Watson, 1995). Scores on all the dimensions seem to be distributed normally (skewness and kurtosis were smaller than one).
The correlation coefficients between the JIQ, AFM 2, OLBI and UWES for employees working in a government organisation are reported in Table 3.

TABLE 3

CORRELATION COEFFICIENTS BETWEEN THE JIQ, AFM 2, OLBI AND UWES

\begin{tabular}{|c|c|c|c|c|c|c|c|}
\hline & & 1 & 2 & 3 & 4 & 5 & 6 \\
\hline 1. & $\begin{array}{l}\text { Cognitive job } \\
\text { insecurity }\end{array}$ & - & - & - & - & - & - \\
\hline 2. & $\begin{array}{l}\text { Affective job } \\
\text { insecurity }\end{array}$ & $0,65^{*} \dagger \dagger$ & - & - & - & - & - \\
\hline 3. & $\begin{array}{l}\text { Engagement } \\
\text { (OLBI) }\end{array}$ & $0,48^{*} \dagger$ & $0,36^{*} \dagger$ & - & - & - & - \\
\hline 4. & $\begin{array}{l}\text { Exhaustion/ } \\
\text { disengagement }\end{array}$ & 0,22 * & 0,22 * & 0,22 * & - & - & - \\
\hline 5. & $\begin{array}{l}\text { Engagement } \\
\text { (UWES) }\end{array}$ & $-0,43^{*} \dagger$ & $-0,30 * \dagger$ & $-0,55^{*} \dagger \dagger$ & $-0,48^{*} \dagger$ & - & - \\
\hline 6. & $\begin{array}{l}\text { Negative } \\
\text { affectivity }\end{array}$ & $0,38 * \dagger$ & $0,32 * \dagger$ & $0,43 * \dagger$ & 0,23 * & $-0,43^{*} \dagger$ & - \\
\hline 7. & $\begin{array}{l}\text { Positive } \\
\text { affectivity }\end{array}$ & $-0,37^{*} \dagger$ & $-0,26^{*}$ & $-0,40^{*} \dagger$ & $-0,28$ * & $0,51 * \dagger \dagger$ & $-0,45^{*} \dagger$ \\
\hline
\end{tabular}

* Statistically significant $\mathrm{p}=0,01$

$\dagger$ Correlation is practically significant $r \geq 0,30$ (medium effect)

$\dagger \dagger$ Correlation is practically significant $r \geq 0,50$ (large effect)

Table 3 shows practically significant negative correlation coefficients of medium effect between the OLBI Exhaustion/Disengagement scale and the UWES. A practically significant negative correlation of large effect was obtained between engagement as measured by the OLBI and engagement as measured by the UWES. For the purpose of interpretation, it must be noted that a high score on the engagement scale of the OLBI suggests low engagement, while a low score indicates increased work engagement. In other words, an increased level of work engagement on the UWES is associated with an increased level of work engagement as measured by the OLBI.

Cognitive job insecurity showed a practically significant positive correlation of medium effect with the OLBI Engagement scale, implying that increased levels of cognitive job insecurity are associated with lower levels of engagement as measured by the OLBI (considering that a lower score indicates higher levels of engagement). In a similar vein, cognitive job insecurity demonstrated a practically significant negative correlation of medium effect with engagement as measured by the UWES, suggesting that higher levels of cognitive job insecurity are associated with lower levels of engagement. Affective job insecurity demonstrated a practically significant correlation of medium effect with engagement as measured by the OLBI, suggesting that higher levels of affective job insecurity are associated with lower levels engagement as measured by the OLBI. No practically significant correlations were obtained between the job insecurity subscales and the exhaustion/disengagement scales of the OLBI, although results were statistically significant.

As expected, a negative correlation of medium effect was obtained between negative and positive affectivity. Negative affectivity demonstrated a positive correlation of medium effect with engagement as measured by the OLBI, suggesting that negative affectivity is associated with lower levels of engagement. Practically significant correlations of medium effect were obtained between negative affectivity and both job insecurity scales, suggesting that higher levels of affective and cognitive job insecurity are associated with higher levels of negative affectivity. A negative correlation of medium effect was obtained between negative affectivity and the 
UWES, also indicating that increased levels of negative affectivity are associated with decreased levels of engagement. Positive affectivity demonstrated a negative correlation of medium effect with engagement as measured by the OLBI, suggesting that increased levels of positive affectivity are associated with increased levels of engagement - a relationship also confirmed by the positive correlation of large effect obtained between positive affectivity and the UWES.

Next, the main and interaction effects of negative and positive affectivity on burnout and work engagement were tested. Work engagement (as measured by the UWES) was not included in the analyses, given its strong correlation with engagement as measured by the OLBI $(r=-0,55$; $p<0,01)$. In order to prepare the data for the analyses of main and interaction effects, the negative and positive affectivity groups were both divided into two groups consisting of scores lower than the 50th percentile and scores higher than the 50 th percentile.

TABLE 4

MANOVA OF JOB INSECURITY, ENGAGEMENT (OLBI), EXHAUSTION/DISENGAGEMENT WITH NEGATIVE AND POSITIVE AFFECTIVITY AS INDEPENDENT VARIABLES

\begin{tabular}{lcccccc}
\hline Variable & Value & $\boldsymbol{F}$ & $\boldsymbol{d f}$ & Error $\boldsymbol{d f}$ & $\boldsymbol{p}$ & $\begin{array}{c}\text { Partial eta } \\
\text { squared }\end{array}$ \\
\hline Negative affectivity & 0,85 & 11,71 & 4 & 270 & $0,000^{*}$ & 0,15 \\
Positive affectivity & 0,82 & 11,82 & 4 & 270 & $0,000^{*}$ & 0,15
\end{tabular}

* Statistically significant difference: $p<0,01$

As indicated by Table 4, there was a significant effect of negative affectivity on the combined dependent variables job insecurity, burnout, and work engagement $\left(\mathrm{F}_{(4,270)}=11,70\right.$, $\mathrm{p}<0,01$; Wilk's Lambda $=0,85$; partial $\left.\eta^{2}=0,15\right)$. This effect was large ( $15 \%$ of the variance explained). Analysis of each individual dependent variable, showed that the groups differed in terms of the level of affective job insecurity $\left(\mathrm{F}_{(1,275)}=14,52, \mathrm{p}<0,01\right.$, partial $\left.\eta^{2}=0,05\right)$, cognitive job insecurity $\left(\mathrm{F}_{(1,275)}=21,07, \mathrm{p}<0,01\right.$, partial $\left.\eta^{2}=0,07\right)$, work engagement, $\left(\mathrm{F}_{(1,275)}=31,98, \mathrm{p}<0,01\right.$, partial $\left.\eta^{2}=0,11\right)$, and exhaustion/disengagement $\left(\mathrm{F}_{(1,275)}=15,13, \mathrm{p}<0,01\right.$, partial $\left.\eta^{2}=0,05\right)$. Employees who scored low on negative affectivity (compared to those with high scores) experienced significantly less job insecurity and burnout and higher levels of work engagement. Therefore, a main effect of negative affectivity on exhaustion/disengagement and work engagement was confirmed.

Table 4 also shows that there was a significant effect of positive affectivity on the combined dependent variables job insecurity, burnout, and work engagement $\left(\mathrm{F}_{(4,270)}=11,82\right.$, $p<0,01$; Wilk's Lambda $=0,85$; partial $\left.\eta^{2}=0,15\right)$. This effect was large ( $15 \%$ of the variance explained). Analysis of each individual dependent variable, showed that the groups differed in terms of the level of affective job insecurity $\left(\mathrm{F}_{(1,275)}=11,04, \mathrm{p}<0,01\right.$, partial $\left.\eta^{2}=0,04\right)$, cognitive job insecurity ${ }_{(\mathrm{F}(1,275)}=15,60, \mathrm{p}<0,01$, partial $\left.\eta^{2}=0,05\right)$, work engagement,

$\left(\mathrm{F}_{(1,275)}=31,42, \mathrm{p}<0,01\right.$, partial $\left.\eta^{2}=0,10\right)$, and exhaustion/ disengagement $\left(\mathrm{F}_{(1,275)}=20,59, \mathrm{p}<0,01\right.$, partial $\left.\eta^{2}=0,07\right)$. Employees who scored high on positive affectivity (compared to those with low scores) experienced significantly less job insecurity and burnout and more work engagement. Therefore, a main effect of positive affectivity on exhaustion/ disengagement and work engagement was confirmed.
Next, the hypothesised structural model (unconstrained) for low and high negative affectivity groups was tested using structural equation modelling as implemented by AMOS (Arbuckle, 1997). Figure 1 shows that structural model for the low and high negative affectivity groups.

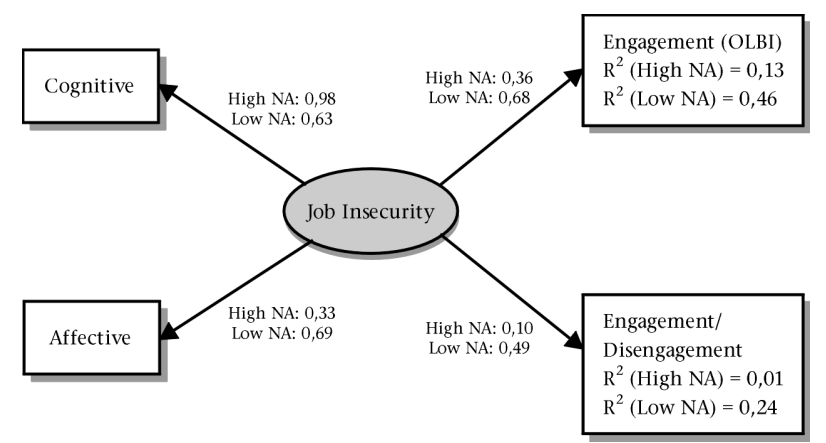

Figure 1: Structural model of job insecurity, burnout, and work engagement of low and high negative affectivity (NA) groups

Upon inspecting the path coefficients from the cognitive and affective subscales to job insecurity, it is evident that individuals categorised as falling within the high negative affectivity group experienced affective and cognitive job insecurity differently. Figure 1 shows that the standardised regression coefficients of cognitive and affective job insecurity were substantially different for high and low negative affectivity groups. Therefore, it is possible that the structure of job insecurity differs for high and low negative affectivity groups. The job insecurity levels of individuals with high negative affectivity were thus more likely to be constituted by their cognitive appraisal, as opposed to their emotional appraisal of potential job loss. The loadings of the cognitive and affective job insecurity subscales on job insecurity were very similar for the low negative affectivity group.

In the unconstrained model (see Figure 1), job insecurity predicted $13 \%$ of the variance in exhaustion/disengagement and $1 \%$ of the variance in work engagement in the high negative affectivity group. In the low negative affectivity group, job insecurity predicted $46 \%$ of the variance in work engagement and $24 \%$ of the variance in exhaustion/disengagement $\left(\chi^{2}=7,34\right.$, $\mathrm{df}=4, \mathrm{p}=0,12$ ).

To test for possible interaction effects between negative affectivity and job insecurity, the paths from job insecurity to exhaustion/disengagement and work engagement were constrained equal for the low and high negative affectivity groups. The constrained model was statistically significantly different from the unconstrained model $\left(\Delta \chi^{2}=10,01 ; \Delta \mathrm{df}=2 ; \mathrm{p}\right.$ $<0,01)$. This result suggests that job insecurity interacted with negative affectivity in affecting exhaustion/disengagement and work engagement. Figure 2 shows the structural model for high and low positive affectivity groups.

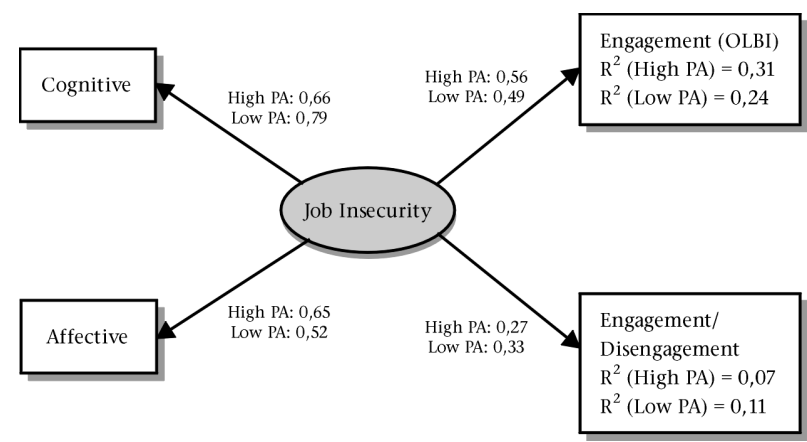

Figure 2: Structural model of job insecurity, burnout and work engagement of low and high positive affectivity (PA) groups 
Figure 2 shows that the standardised regression coefficients of cognitive and affective job insecurity were comparable in the low and high positive affectivity groups. In the unconstrained model (see Figure 2), job insecurity predicted $31 \%$ of the variance in exhaustion/disengagement and $7 \%$ of the variance in work engagement in the high positive affectivity group. In the low positive affectivity group, job insecurity predicted $24 \%$ of the variance in work engagement and $11 \%$ of the variance in exhaustion/disengagement $\left(\chi^{2}=1,85, \mathrm{df}=4, \mathrm{p}=0,76\right)$.

To test for possible interaction effects between positive affectivity and job insecurity, the paths from job insecurity to exhaustion/disengagement and work engagement were constrained equally for the low and high positive affectivity groups. The constrained model was not statistically significantly different from the unconstrained model $\left(\Delta \chi^{2}=1,79 ; \Delta d f=2 ; p\right.$ $>0,05)$. This result suggests that job insecurity did not interact with positive affectivity in impacting on exhaustion/ disengagement and work engagement.

\section{DISCUSSION}

The objective of this study was to investigate the relationship between job insecurity, burnout and work engagement. The analysis of Pearson correlations showed that higher levels of cognitive job insecurity were associated with lower levels of work engagement (as measured by both the OLBI and the UWES), higher levels of negative affectivity and lower levels of positive affectivity. Increased levels of affective job insecurity demonstrated an association with decreased levels of engagement (both as measured by the OLBI and the UWES) and increased levels of negative affectivity. Negative affectivity was found to be associated with decreased work engagement (as measured by both the OLBI and the UWES). Higher levels of positive affectivity showed an association with higher levels of work engagement (both as measured by the OLBI and the UWES).

A statistically significant relationship was found between job insecurity and burnout. This finding confirms the findings of Westman, Etzion and Danon (2001), and Dekker and Schaufeli (1995). Maslach et al. (2001) also stated that the violation in the psychological contract caused by a lack of job security would lead to burnout. However, in this study the relationship between job insecurity and burnout was not very strong. In the context of the OLBI, which was used to measure burnout in this study, burnout is viewed as the result of prolonged and intense physical, cognitive and affective strain (Demerouti et al., 2002). In terms of this definition, one would expect an employee to develop burnout after experiencing particularly severe job insecurity for a prolonged period of time - which was probably not the case in this sample.

Both job insecurity subscales were consistently associated with decreased levels of work engagement. According to Maslach et al. (2001), the violation of the psychological contract caused by, inter alia, job insecurity, is likely to produce a reduction in work engagement, because it erodes the notion of reciprocity, which is crucial in maintaining well-being. Based on the above findings, hypotheses 1 and 2 could be accepted.

MANOVA indicated that negative affectivity had a large and significant effect on the combined dependent variables (job insecurity, burnout and work engagement). Participants with low negative affectivity scores (compared to those with high scores) displayed significantly less job insecurity and burnout, and higher levels of work engagement. A main effect of negative affectivity on exhaustion/disengagement and work engagement was thus confirmed. Furthermore, it was shown that positive affectivity had a large and significant effect on the combined dependent variables (job insecurity, burnout and work engagement). Participants in the high positive affectivity category (compared to those with low scores) experienced significantly less job insecurity and burnout, and more work engagement. Hypothesis 3 is therefore accepted.

The results seem to indicate that the structure of job insecurity differs for low and high negative affectivity groups. Cognitive job insecurity loaded strongly, while affective job insecurity loaded less strongly on job insecurity in the high negative affectivity group (while loadings of the two scales were similar in the low negative affectivity group). More research is needed to examine why the structure of job insecurity is not invariant for employees who measured low and high on negative affectivity.

In addition to the main effect of negative affectivity on burnout and work engagement, negative affectivity also interacted with job insecurity to affect burnout and work engagement levels. Constraining the parameters equal between job insecurity on the one hand and burnout and work engagement on the other hand for the low and high negative affectivity groups, resulted in a significant difference from the unconstrained model. The standardised regression coefficients between job insecurity, burnout and work engagement were quite strong for the low negative affectivity groups, while these coefficients were less strong for the high negative affectivity group. At low levels of negative affectivity, job insecurity strongly predicted burnout and low work engagement. However, at high levels of negative affectivity, job insecurity predicted burnout and low work engagement less strongly. It is therefore clear that the relationships between job insecurity on the one hand and burnout and work engagement on the other hand manifested differently for employees who measured low compared to those who measured high on negative affectivity.

Although positive affectivity had a main effect on burnout and work engagement, no support was obtained for the notion that positive affectivity would interact with job insecurity to affect burnout and work engagement levels. Hypotheses 4 could thus only be partially accepted.

Based upon the findings of this research, it can be concluded that individuals who experience job insecurity, experience less work engagement, and more exhaustion and disengagement at work. Furthermore, individuals experiencing low levels of positive affectivity and high levels of negative affectivity also experience lower levels of work engagement and higher levels of exhaustion/disengagement. Besides the main effects of negative and positive affectivity on burnout and work engagement, an individual's level of negative affectivity interacts with his/her job insecurity level to affect burnout and work engagement levels.

This study had several limitations. Firstly, the sample size is a limitation, specifically the distribution of cultural groups. Stratified random sampling might ensure sufficient representation of the different groups. A further limitation of this study was its reliance on self-report measures. According to Schaufeli, Enzmann and Girault (1993), the exclusive use of self-report measures increases the likelihood that at least part of the shared variance between measures can be attributed to method variance. Regarding research design, future studies should focus on longitudinal designs where causal inferences can be made.

\section{RECOMMENDATIONS}

The results demonstrated that job insecurity contributes toward increased exhaustion/ disengagement and decreased work engagement, that positive and negative affectivity are related to increased exhaustion/disengagement and decreased work engagement, and that negative affectivity interacts with job 
insecurity to affect exhaustion/disengagement and work engagement. Job insecurity levels, as well as positive and negative affectivity levels, need to be addressed in order to secure optimal wellness of employees.

Regarding mechanisms to reduce job insecurity, Barker (1999) found perceived fairness to be a major concern for employees in terms of job insecurity, as job insecurity levels are affected by how employees feel processes in the organisation are fairly managed. Sadri (1996) emphasises the importance of open communication in fostering perceptions of fairness. According to Hiltrop (1996), companies can no longer rely on traditional methods and techniques to attract and retain talented employees and for this reason new kinds of incentives need to be applied. Companies need to find new creative ways of making work challenging and participative, which can lead to a sense of loyalty, which translates into a new kind of security, coined "employability security" (Kanter, 1994). As indicated by Hiltrop (1996), this is the promise that the employee's skills will be enhanced, and that access to other tasks and assignments will be facilitated. Büssing (1999) found that social support had an alleviating function for persons working under job insecure conditions.

Watson (2002) notes that high positive affect is most likely when a person is focused outward and is actively engaged in the environment. Socialisation and interpersonal behaviour, as well as exercise and physical activity, are particularly conducive to positive affectivity. Furthermore, positive affectivity is likely to be increased when employees perceive their goals as important and worthwhile. Employees should be taught how to monitor their moods and to become sensitive to their internal rhythms, which will enable them to maximise feelings of efficacy and enjoyment, while minimising stress and frustration.

More research regarding the relationship between job insecurity and psychological well-being is required in a variety of occupational settings in South Africa. The finding that cognitive job insecurity appears to play a stronger role than affective job insecurity in the case of individuals with high negative affectivity, is significant and would be an interesting area for further exploration of the equivalence of the job insecurity construct for employees with high and low negative affect. It is recommended that a more powerful sampling method be used and that longitudinal designs be employed in order to enable causal inferences. The use of larger samples might also provide increased confidence that study findings would be consistent across other (similar) groups.

\section{REFERENCES}

Abraham, R. (1998). Emotional dissonance in organizations: A conceptualisation of consequences, mediators and moderators. Leadership and Organization Development Journal, 19 (3), 137-146.

Arbuckle J.L. (1997). Amos users' guide version 4.0. Chicago, IL: Smallwaters Corporation.

Ashford, S.J., Lee, C. \& Bobko, P. (1989). Content, causes and consequences of job insecurity: A theory-based measure and substantive test. Academy of Management Journal, 32, 803-829.

Barker, M. A. (1999). Toward an understanding of factors affecting perceptions of job insecurity in downsizing survivors. Humanities and Social Sciences, 60, 5A, 1654.

Baron, R.M. \& Kenny, D.A. (1986). The moderator-mediator variable distinction in social psychological research: Conceptual, strategic, and statistical considerations. Journal of Personality and Social Psychology, 51, 1173-1182.

Baruch, Y. \& Hind, P. (1999). Perpetual motion in organizations: Effective management and the impact on the new psychological contracts on "survivor syndrome". European Journal of Work and Organizational Psychology, 8, 295-306.
Bergh, Z. \& Theron, A. (2003). Psychology in the work context (2nd ed.). Cape Town: Oxford University Press.

Borg, I. \& Elizur, D. (1992). Job insecurity: Correlates, moderators and measurement. International Journal of Manpower, 13, 13-26.

Bridges, W. (1995). Jobshift: How to prosper in a workplace without jobs. Reading, MA: Addison-Wesley.

Büssing, A. (1999). Can control at work and social support moderate psychological consequences of job insecurity? Results from a quasi-experimental study in a steel industry. European Journal of Work and Organizational Psychology, 8, 219-242.

Caplan, R.D., Cobb, S., French, J.R.P., van Harrison, R.V. \& Pinneau, S.R. (1980). Job demands and worker health: Main effects and occupational differences. Ann Arbor, MI: Survey Research Centre, Institute of Social Research, University of Michigan.

Chiu, R.K. \& Kosinski, F.A. (1997). Relationships between dispositional traits and self-reported job satisfaction and distress. Journal of Managerial Psychology, 12, 71-84.

Clark, L.A. \& Watson, D. (1995). Construct validity: Basic issues in objective scale development. Psychological Assessment, 7, 309-319.

Cohen, J. (1988). Statistical power analysis for behavioral sciences ( $2^{\text {nd }}$ ed.). Hillsdale, NJ: Lawrence Erlbaum \& Associates.

Dekker, S.W. \& Schaufeli, W.B. (1995). The effect of job insecurity on psychological health and withdrawal: A longitudinal study. Australian Psychologist, 30, 57-63.

Demerouti, E., Bakker, A.B., Nachreiner, F. \& Ebbinghaus, M. (2002). From mental strain to burnout. European Journal of Work and Organizational Psychology, 11, 423-441.

Demerouti, E., Bakker, A.B., Vardakou, I. \& Kantas, A. (2003). The convergent validity of two burnout instruments: A multitrait-multimethod analysis. European Journal of Psychological Assessment, 19, 12-23.

De Witte, H. (1997, April). Long-term job insecurity as a stressor: Its impact on satisfaction and commitment. Paper presented at the $8^{\text {th }}$ European Congress on Work and Organizational Psychology, Verona, Italy.

De Witte, H. (1999). Job insecurity and psychological well-being: Review of the literature and exploration of some unresolved issues. European Journal of Work and Organizational Psychology, 8, 155-177.

De Witte, H. (2000). Arbeidethos en jobonzekerheid: Meting en gevolgen voor welzijn, tevredenheid en inzet op het werk. [Labour ethics and job insecurity. Measurement and consequences for well-being, satisfaction and labour input.] In Bouwen, R., De Witte, K., De Witte, H. \& Taillieu, T. (Ed.), Van groep tot gemeenschap. Liber Amicorum Prof. Dr. L. Lagrou. Leuven: Garant.

Elbert, J. (2002). Job insecurity, and psychological strengths of service workers in a parastatal. Unpublished master's dissertation, Vaal Triangle Campus of the Potchefstroom University, Vanderbijlpark.

Ferrie, J.E. (1997). Labour market status, insecurity and health. Journal of Health Psychology, 2, 155-170.

Greenhalgh, L. \& Rosenblatt, Z. (1984). Job insecurity: Towards conceptual clarity. Academy of Management Review, 9, $438-448$.

Hellgren, J., Sverke, M. \& Isaksson, K. (1999). A two-dimensional approach to job insecurity: Consequences for employee attitudes and well-being. European Journal of Work and Organizational Psychology, 8, 179-195.

Heymans, D.R. (2002). Job insecurity, job satisfaction and organisational commitment. Unpublished master's dissertation, Potchefstroom University for CHE, Vanderbijlpark, South Africa.

Hiltrop, J.M. (1996). Managing the psychological contract. Employee Relations, 18 (1), 36-49.

Jackson, L.T.B. \& Rothmann, S. (2004). A model of work-related well-being for teachers in the North West Province. Poster presented at the $2^{\text {nd }}$ European Positive Psychology Conference, Verbania Pallanza, Italy. 
Jacobson, D. (1991). The conceptual approach to job insecurity. In Hartley, J., Jacobson, D., Klandermans, B. \& Van Vuuren, T. (Eds.), Job insecurity: Coping with jobs at risk (pp. 23-39). London: Sage Publications.

Joelson, L. \& Wahlquist, L. (1987). The psychological meaning of job insecurity and job loss: The results of a longitudinal study. Social Science and Medicine, 25, 179-182.

Kammann, R. \& Flett, R. (1983). Affectometer 2: A scale to measure current levels of general happiness. Australian Journal of Psychology, 35, 259-265.

Kanter, R.M. (1994). Change in the global economy: An interview with Rosabeth Moss Kanter. European Management Journal, 12 (1), 1-9.

Landsbergis, P.A. (1988). Occupational stress faced by health care workers: A test of the job demands-control model. Journal of Organizational Behavior, 9, 217-239.

Mak, A.S. \& Mueller, J. (2001). Negative affect, perceived occupational stress, and health during organisational restructuring: A follow-up study. Psychology and Health, 16, 125-137.

Martins, N. (2000). Developing a trust model for assisting management during change. Journal of Industrial Psychology, 26 (3), 27-31

Maslach, C. \& Leiter, M.P. (1997). The truth about burnout. San Francisco, CA: Jossey-Bass.

Maslach, C., Schaufeli, W.B. \& Leiter, M.P. (2001). Job burnout. Annual Review of Psychology, 52, 397-422.

Meeks, S. \& Murrell, S.A. (2001). Contribution of education to health and life satisfaction in older adults mediated by negative affect. Journal of Aging and Health, 13, 92-120.

Nunnally, J.C. \& Bernstein, I.H. (1994). Psychometric theory (3rd ed.). New York: McGraw-Hill.

Parkes, K.R. (1994). Personality and coping as moderators of work stress processes. Models measures and methods. Work and Stress, 8, 110-129.

Probst, T.M. (2002). The impact of job insecurity on employee work attitudes, job adaptation, and organisational withdrawal behaviours. In J.M. Brett \& F. Drasgow (Eds.), The psychology of work: Theoretically based empirical research (pp. 141-168). Mahwah, NJ: Lawrence Erlbaum.

Rosenblatt, Z. \& Ruvio, A. (1996). A test of a multidimensional model of job insecurity: The case of Israeli teachers. Journal of Organizational Behaviour, 17, 587-605.

Roskies, E., Louis-Guerin, C. \& Fournier, C. (1993). Coping with job insecurity: How does personality make a difference? Journal of Organizational Behavior, 14, 617-630.
Rothmann, S. (2003). Burnout and engagement: A South African perspective. SA Journal of Industrial Psychology, 29 (4), 16-25.

Rothmann, S., Jackson, L.T.B. \& Kruger, M.M. (2003). Burnout and job stress in a local government: The moderating effect of sense of coherence. SA Journal of Industrial Psychology, 29 (4), 52-60.

Sadri, G. (1996). Reflections: the impact of downsizing on survivors - some findings and recommendations. Journal of Managerial Psychology, 11, 56-59.

Schaufeli, W.B. \& Bakker, A.B. (2002). Job demands, job resources and their relationship with burnout and engagement: A multisample study on the COBE model. Utrecht University: Psychology and Health.

Schaufeli, W.B. \& Enzmann, D. (1998). The burnout companion to study and practice: A critical analysis. London: Taylor \& Francis.

Schaufeli, W.B., Enzmann, D. \& Girault, N. (1993). Measurement of burnout: A review. In W.B Schaufeli, C. Maslach \& T. Marek (Eds.), Professional burnout: Recent develops in theory and research (pp. 199-215). Washington, DC: Taylor \& Francis.

Schaufeli, W.B., Salanova, M., González-Romá, V. \& Bakker, A.B. (2002). The measurement of engagement and burnout: A confirmatory factor analytic approach. Journal of Happiness Studies, 3, 71-92.

Siegrist, J., Starke, D., Chandola, T., Godin, Il, Marmot, M., Niedhammer, I. \& Peter, R. (2004). The measurement of effort-reward imbalance at work: European comparisons. Social Science and Medicine, 58, 1483-1499.

Shaughnessy, J.J. \& Zechmeister, E.B. (1997). Research methods in psychology (4th ed.). New York: McGraw-Hill.

SPSS Inc. (2003). SPSS 12.0 for Windows. Chicago, IL: Author.

Steyn, H.S. (2002). Practically significant relationships between two variables. SA Journal of Industrial Psychology, 28 (3), $10-15$.

Storm, K. (2002). Burnout and engagement in the South African Police Services. Unpublished doctoral thesis, PU for CHE, Potchefstroom.

Van Vuuren, T. (1990). Met ontslag bedreigd. Werknemers in onzekerheid over hun arbeidsplaats bij veranderingen in de organisatie. Amsterdam: VU Uitgeverij.

Watson, D. (2002). Positive affect: The disposition to experience pleasurable emotional states. In C.R. Snyder \& S.J. Lopez (Eds.). Handbook of positive psychology (pp. 106-119). Oxford, UK: Oxford University Press.

Westman, M., Etzion, D. \& Danon, E. (2001). Job insecurity and crossover of burnout in married couples. Journal of Organizational Behavior, 22, 467-481. 